\begin{tabular}{lllll}
\hline \hline $\mathbf{N}$ & $\mathbf{O}$ & $\mathrm{T}$ & $\mathbf{A}$ & $\mathrm{S}$
\end{tabular}




\section{LOS DEBERES FUNDAMENTALES *}

A) El Origen Histórico.

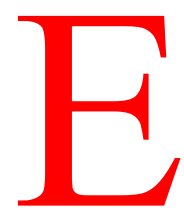

1 concepto de deber aparece en la historia en el ámbito ético y religioso. Como otros muchos conceptos jurídicos su origen es inseparable de la dimensión religiosa como era en los primeros tiempos todo el Derecho (Fustel de Coulanges).

La influencia decisiva de la idea de deber en el Derecho se empezará a producir a partir del tránsito a la modernidad con la aportación del estoicismo al humanismo jurídico primero y al iusnaturalismo racionalista después (Villey).

Ya en Roma el estoicismo había influido en Cicerón y a su través conceptos morales se habían trasladado al ámbito jurídico. Su tratado sobre los deberes (De Officiis) será clave en ese sentido para la recepción en el Derecho moderno del concepto de deber. El contexto social, político, económico y cultural a partir del siglo XVII, favorecerá el trasvase desde el ámbito moral al jurídico. El individualismo en una situación fundamentalmente antropocéntrica orientará al Derecho desde su búsqueda en las relaciones objetivas, lo que es justo en cada caso (concepción medieval), a la actitud del individuo ante las normas. Los deberes serán consecuencia de este nuevo punto de vista.

Ya la Reforma protestante aplicará una moral estricta, donde las prescripciones de la Ley judía, referentes al comportamiento social, se convierten en norma. Así la obligación de trabajar, el respeto y la lealtad a lo pactado, el deber de respetar la propiedad (Calvino). Pero será con el humanismo jurídico cuando la influencia de Cicerón incorporará el tema de los deberes al Derecho. El contenido de lo justo empezará a coincidir con el cumplimiento del deber por el individuo (De República, Cicerón). Entre las inclinaciones del hombre que son exclusivamente suyas están deberes centrales como no dañar a nadie, no impedir a nadie conservarse, vestirse, enriquecerse, estar al servicio de los demás y también no robar y no faltar a la palabra. En un proceso complicado, vinculado al interés de la burguesía en la orientación del Derecho se pasará del deber de no robar al Derecho de propiedad y del cumplimiento de las promesas al contractualismo moderno.

Este punto de vista influirá en el humanismo jurídico y en el iusnaturalismo. Se hablará del deber de sociabilidad, y de los deberes de no dañar a los demás, de restituir lo ajeno, de mantener la palabra, de reparar el daño y se añade que la violación de esas reglas merece castigo, incluso

\footnotetext{
* Este trabajo es la segunda parte de la voz «Diritti e Doveri Fondamentali», enviado en italiano para ser publicado en la nueva edición del Novissimo Digesto.
} 
de los hombres (Grocio). El deber pasa de la moral al Derecho y ya se encuentra el rasgo del castigo como elemento identificador.

Así, ya en el iusnaturalismo racionalista se llamará deber a una acción humana exactamente conforme a las Leyes que imponen la obligación (Pufendorf) y se desarrollarán los aspectos que generan ese vínculo de hacer o no hacer.

De estos deberes de los hombres (no hacer daño a nadie y reparar el daño causado, considerarse como naturalmente iguales, contribuir a la utilidad de los demás, cumplir con la palabra dada, no enfadar a nadie, cumplir los compromisos, respetar la propiedad, etc.) surge el sistema de Derecho natural y el concepto de derecho subjetivo.

Ya con Hobbes, con un sistema intelectual similar el primer deber real de todo súbdito será obedecer al Derecho positivo. El deber será el cumplimiento del mandato de aquel cuyo mando se dirige a alguien previamente obligado a obedecer. En definitiva la única función del Derecho Natural será legitimar la obediencia al Derecho positivo y éste será la fuente de la obligación (Bobbio).

Con Kant se llegará a una ética de los deberes y a su distinción respecto de los deberes jurídicos. Así la legislación que convierte una acción en obligatoria y que a su vez hace de esta obligación el motivo del obrar es ética. Cuando esto no es así, y el deber permite un motivo del obrar distinto de la obligación misma, estamos ante una obligación jurídica. Así las obligaciones derivadas de la legislación jurídica sólo pueden ser obligaciones externas, las derivadas de la legislación ética se generan por acciones internas.

La afirmación de que los deberes jurídicos derivan de la existencia de una norma jurídica que los establece, empezará a tomar cuerpo en el origen de la crisis del iusnaturalismo a finales del siglo XVIII y se consolidará a partir del siglo XIX.

b) Cuando los deberes se incorporan al Derecho positivo, especialmente al nivel superior, paralelos a los derechos fundamentales, lo hacen desde posiciones moderadas que pretenden limitar los efectos de los derechos como levadura revolucionaria.

Ya en la voz «Súbditos» de la Enciclopedia se dividen los deberes en generales y particulares derivados del estado y situación del súbdito. Puesto que todos los súbditos tienen en común que están sometidos a un mismo soberano y gobierno, de esas relaciones derivan los deberes generales. Quizás en esta identificación se encuentra la raíz del concepto de deberes fundamentales, como aquellos que derivan de la relación del súbdito con el poder soberano. Posteriormente los deberes fundamentales no serán sólo del súbdito, sino que con el sometimiento del gobernante al Derecho y con la aparición del Estado social, se podrá hablar también de deberes fundamentales de los poderes públicos.

Entre estos deberes generales distinguirá la Enciclopedia aquellos que relacionan a los súbditos con los gobernantes, con el cuerpo político en general y con los individuos que son ciudadanos.

Por otra parte, los deberes particulares derivan de los diferentes empleos y posiciones que ocupan dentro del Estado y de las diversas profesiones que ejercen. 
Esta relación entre derechos y deberes se extiende a obras como la de Mably (De los derechos y de los deberes del ciudadano, 1758) aunque luego no encontremos en su interior una auténtica teoría de los deberes.

En los orígenes de la revolución francesa las declaraciones de derechos del hombre y del ciudadano de 1789 y de 1793, esta última con influencia jacobina y especialmente de Robespierre, no se refieren a los deberes. Sin embargo, la Constitución del año III, 1795, sí que contiene una declaración de deberes.

Esto se entiende en una situación más moderada tras la caída de Robespierre, en la toma del poder por los termidorianos. Estos tenían serias discrepancias con la Constitución «montagnarde» de 1793, que nunca entró en vigor, y especialmente con sus derechos sociales.

Mucho más influida por Montesquieu, y huyendo de la influencia de Rousseau, la Constitución abandona el sufragio universal e incluso se discute por algunos miembros de la Convención, la necesidad de una declaración de derechos, que podía servir de punto de referencia a las aspiraciones democráticas y revolucionarias. Se eliminaron algunas expresiones de 1789 como «los hombres nacen y permanecen libres e iguales en derechos». En este contexto se sitúa la declaración de deberes ( 9 artículos) donde se afirma que «la declaración de derechos contiene las obligaciones del legislador; el mantenimiento de la sociedad exige que los que la componen conozcan y cumplan igualmente sus deberes» (art. 1. ${ }^{\circ}$ ). Son sólo deberes de los ciudadanos no de los gobernantes.

Los deberes parten de los principios de no hacer a los demás lo que no queremos que nos hagan a nosotros, y hacer el bien que quisiéramos recibir (art. 2. ${ }^{\circ}$ ). Así se debe servir a la sociedad, vivir sometido a las leyes y respetar a sus órganos, mantener y respetar las propiedades, y defender a la patria y a sus principios de libertad, de igualdad y de propiedad cada vez que se sea llamado a ello.

En esta primera ocasión en que se positivizan los deberes se hace al servicio de una sociedad que desconfía de la libertad y de la soberanía popular, que defiende los intereses de los propietarios y como contrapeso de una Declaración de derechos debilitada en relación con 1789.

Este rasgo de desconfianza en los derechos y en los componentes progresistas de la libertad, se expresará en la organización política de los Estados autoritarios (Italia, Alemania, Portugal y España) que recogerán también más los deberes de los ciudadanos respecto al poder que sus derechos.

Pero los deberes fundamentales se incorporarán también a la cultura jurídica en textos Constitucionales más progresistas, aunque, como en el caso de la Constitución Francesa de 1848, sólo a través del preámbulo que carecía de carácter normativo.

Es importante que los deberes se planteen como deberes recíprocos de los ciudadanos respecto a la República y de la República respecto de los ciudadanos (V). Entre los primeros se señala el amor a la Patria, el servicio y la defensa de la República, la participación en los cargos públicos en proporción a la fortuna, el deber del trabajo y de obediencia a las normas morales y jurídicas (VI). Por su parte la República debe proteger al ciudadano, en su persona, su familia, su religión, su propiedad, 
su trabajo, ofrecen la educación indispensable a todos los hombres, procuran asistencia sea por medio de trabajo, sea protegiendo, en defecto de la familia, a quienes no lo tienen (VII).

La Constitución se establece para cumplir esos deberes y para garantizar esos derechos.

En el constitucionalismo posterior, con independencia del carácter progresista o moderado del texto de que se trate, se incorporan los deberes fundamentales de los ciudadanos, especialmente los que se refieren al sostenimiento de las cargas públicas (deber de pagar los impuestos) y a la defensa de la nación (deber de prestación del servicio militar). Así la Constitución de Weimar (art. 120, 132, 133, 134, 163) y la española de 1931 (arts. 37, 43, 46, 48, 115). En la actualidad encontramos esos deberes fundamentales en la Constitución Italiana (arts. 2, 4, 30, 34, 48, 52, 53, 54); en la Alemana (6.2, 12a, 33.1), en la portuguesa (parte I) y en la Española (arts. 3, 27.4, 30, 31, 32.2, 35.1, 39.3, 118, 139) entre otras.

Los deberes fundamentales lo serán también de los poderes públicos, de los órganos y de los funcionarios a partir de la entrada en juego de dos criterios.

1) En primer lugar el Estado de Derecho, el sometimiento de los gobernantes a la Ley, con la superación del principio «princeps a legibus solutus», propio del Estado absoluto y de la inicial concepción de la soberanía en Bodino, supone que las normas jurídicas regulan también el origen, la organización y el funcionamiento del poder. De este principio general se deduce la posibilidad de que los poderes públicos sean titulares de deberes jurídicos, y, en este caso, de deberes jurídicos fundamentales.

2) En segundo lugar el paso del Estado liberal al Estado social de Derecho atribuirá unas funciones positivas al poder público para la satisfacción igual de las necesidades humanas básicas. Es conocido este proceso y sólo se debe consignar que una serie de deberes de prestación de servicios son consecuencia de esas funciones que se asumen por las instituciones y que a veces esos deberes son consecuencia de derechos de crédito de los ciudadanos cuyo ejercicio desencadena el deber de la prestación.

No estamos ya sólo ante el deber negativo de abstención en la esfera de autonomía garantizada por los derechos individuales, ni siquiera ante el deber de aceptar la participación de los ciudadanos en la formación de la voluntad del poder, sino ante un deber positivo que exige la realización de acciones.

Los textos constitucionales actuales (con precedentes que arrancan de 1848) recogen estos deberes fundamentales de los poderes públicos. Así la Constitución Italiana (arts. 2, $3,9,30,31,32,34,35$, etc.) o la española (arts. 9.2, 27, 3, 5 y 9, 39, 40, 41, 42.2, 44, etc.).

Hay que señalar por fin que también alguna Constitución actual establece el sometimiento recíproco, de gobernantes y gobernados al Derecho, es decir el deber de obediencia a las normas jurídicas, problema muy discutido y al que nos referimos más adelante. Así la Constitución Española donde se afirma que «los ciudadanos y los poderes públicos 
están sujetos a la Constitución y al resto del Ordenamiento jurídico (art. 9-1). Otras Constituciones afirman sólo la obligación general de obediencia respecto a los ciudadanos (Constitución Italiana art. 54) mientras que en otras se afirman vinculaciones de partes del Ordenamiento, también para los poderes públicos (Ley Fundamental de Bonn, art. 1.3).

\section{B) Concepto de Deberes Fundamentales.}

a) Como se desprende del panorama histórico, el concepto de deber ha sido decisivo junto con la identificación del Derecho con Ley, para la formación del Derecho moderno. También lo es en importantes doctrinas contemporáneas (Kelsen, Scarpelli).

La identificación del deber jurídico y su distinción del deber moral es imprescindible para aclarar el sentido del término deber fundamental.

Descartamos aquellas posiciones, como las del realismo escandinavo, que desvalorizan el concepto de deber jurídico al que se atribuye una función ideológica (Ross) un sentido ideal, una idea referida a su poder sobrenatural (Hägeström) o simplemente la consideración de una quimera que debía ser excluida del discurso científico (Lundstedt) o que carece de referencia fáctica y que no significa nada en absoluto (Olivecrona).

Se han producido importantes aportaciones a lo largo de la historia de la cultura jurídica reciente para acotar el concepto de deber jurídico (Bellagio 1965), e incluso en una de ellas se ha ensayado una tipología de las principales teorías de la obligación jurídica según el modo con el que se ha intentado definir el concepto de deber y según la posición que se ha atribuido al concepto de deber en el sistema de los conceptos jurídicos (Bobbio).

El concepto de deber jurídico que utilizamos es el que han propuesto filósofos y teóricos del Derecho, es decir, el que pretende estipular un uso para el concepto; válido para cualquier Ordenamiento, y en concreto para acercarnos después al concepto de deberes fundamentales. No describimos el uso del término que se hace en los diferentes Derechos positivos, ni tampoco su utilización en la ciencia jurídica, con referencia a un lenguaje de un sistema jurídico concreto.

Bentham usará una definición predictiva al señalar que tener un deber significa que la persona que se encuentra en esa situación, si no se comporta como aquel establece, sufrirá un mal (un dolor, una falta de placer). Esta probabilidad de sufrir un mal si se omite un deber (sea de hacer o de no hacer) será jurídica cuando el sufrimiento es infligido por un funcionario de acuerdo con el Derecho.

Una posición parecida se encuentra en Holmes, para quien obligación y deber jurídico no es sino la predicción de que si una persona realiza o deja de realizar ciertos actos deberá sufrir la sanción de un Tribunal de Justicia.

No es sin embargo una aproximación útil porque muchas veces se tiene una obligación y no se sufre ningún mal si se incumple (no se es descubierto, condenado o penado), o a veces uno se ve obligado a hacer algo bajo amenaza de un mal y no estamos ante un deber jurídico (el ladrón que amenaza para robar). La distinción entre «se ve obligado a 
hacer algo» y «tenía la obligación de hacerlo» (Hart) es esclarecedora para señalar lo improcedente de esta aproximación predictiva al deber jurídico, propia del utilitarismo, de gran influencia en la cultura anglosajona.

Un segundo modelo a considerar es el de Kelsen, asimismo de gran influencia en la cultura continental. Coherentemente con el conjunto de su teoría vinculará obligación con sanción, puesto que una conducta sólo puede ser ordenada jurídicamente en forma objetiva y en un deber atribuible a alguien, si una norma jurídica imputa a la conducta contraria un acto coactivo como sanción. Tiene un deber y está jurídicamente obligado el individuo que puede cometer con su conducta un acto ilícito, pudiendo así producir la sanción, y a su vez puede evitar la sanción realizando la conducta opuesta, que es el contenido de su deber. (Teoría pura del Derecho). Esta aproximación al concepto de deber jurídico dificulta la construcción de una teoría de los deberes fundamentales para los órganos funcionarios o instituciones del máximo nivel, puesto que a la conducta contraria a la que supondría su deber fundamental, no está en esos casos imputada por una sanción.

Hay una diferencia entre el modelo de Bentham Austin, Holmes (predictivo) y el modelo de Kelsen (normativo), pero en ambos es central la idea de sanción y la coactividad del Derecho (Carrió). La solidez interna y la trabazón lógica del sistema Kelseniano a veces le distancia de la realidad, y le impide, para ser coherente, ser útil. Deslumbra pero no ilumina.

La concepción de Hart es el tercer modelo que vamos a considerar.

Parte de la crítica a las posiciones predictivas, puesto que la existencia de un deber jurídico puede no coincidir con la existencia de una sanción a causa de la desobediencia. Por otra parte, el deber jurídico se basa en normas previas y en ese caso su desobediencia no sirve sólo para predecir la existencia de sanciones, es también la razón que legitima esa sanción.

Parte Hart para identificar a un deber jurídico de la existencia de normas que permiten fundar la obligación y consiguientemente enjuiciar el comportamiento del obligado:

1) Para que la norma imponga obligaciones debe existir una exigencia general en favor de la conformidad y ésta ser insistente y la presión social respecto a las actitudes desviantes debe ser grande. Aún así no basta para sostener la existencia de un deber jurídico (puede ser moral o de etiqueta o cortesía).

2) Es preciso además que la norma sea considerada importante y necesaria para la preservación de la vida social.

3) Es normal además que la conducta exigida por el deber, aunque sea beneficiosa para otros, pueda implicar sacrificio y renuncia para el titular del deber.

4) La norma debe otorgar competencia para la exigencia del cumplimiento del deber a los poderes públicos (Derecho penal) o dejar a un particular que pueda optar entre exigir o no el cumplimiento (Derecho civil).

Insiste también en este caso en su distinción entre el aspecto interno y externo de las normas. Desde el punto de vista interno se entiende la 
manera en que las normas funcionan como tales en la vida de los que forman esa sociedad y usan esas normas. Los operadores jurídicos y los ciudadanos usan esas normas como guía para organizar la vida social. La violación de una norma que establece un deber no es sólo la base para la predicción de una sanción, sino una razón para justificarla. Es necesaria la aceptación efectiva como actitud normativa de los usuarios de las normas.

5) En un sistema jurídico moderno los deberes jurídicos necesitan junto a las normas que los recogen (normas primarias) otro tipo de normas que establecen la competencia para determinar si se ha transgredido una norma primaria y para aplicar en su caso una sanción (es el tercer tipo de normas secundarias llamadas por Hart normas de adjudicación).

b) Con estos antecedentes se puede estipular un concepto de deber jurídico presupuesto necesario para hablar de deberes jurídicos fundamentales:

1) El deber jurídico existe con independencia de que el deber de que se trata haya tenido previamente o no una dimensión moral (el deber de no injuriar o calumniar y el deber de conducir por la derecha son ambos deberes jurídicos de origen distinto). Sólo el deber jurídico será relevante, igual que el derecho subjetivo, la libertad, la potestad o la inmunidad para el Derecho, con independencia de la influencia o de la presión que pueden producir aquellas dimensiones morales que engendran obligaciones a ese nivel, y de la posibilidad de que se conviertan en obligaciones jurídicas. Todo esto sin perjuicio de que esa influencia de la moralidad pueda orientar las decisiones de los operadores jurídicos.

2) El deber jurídico tiene que estar reconocido por una norma perteneciente al Ordenamiento. Eso supone su creación de acuerdo con la norma de identificación de normas que establece los órganos competentes y los procedimientos adecuados para crear normas y el apoyo del sistema en el poder -hecho fundante básico- entendido como conjunto de instituciones, poderes, operadores jurídicos y ciudadanos que creen en los valores que sustentan ese ordenamiento, que participan en su formación, que apoyan y aceptan su norma de identificación de normas y que usan las normas que contiene. Entre ellas las que establecen deberes jurídicos. Este requisito incluye todos los que Hart considera imprescindibles.

3) Normalmente los deberes jurídicos llevan aparejada una sanción en caso de incumplimiento y ésta consiste en una pena o en la ejecución forzosa a cargo de quien tiene ese deber (en el supuesto de que sea posible) o una indemnización en otro caso. A veces los deberes positivos pueden ser incentivados a través de una sanción positiva o premio.

Pero pueden existir deberes cuyos titulares no puedan ser sancionados en el sentido clásico del término (como los poderes del Estado. Así el ejecutivo tiene la obligación de presentar los presupuestos ante las Cámaras antes del $1 .^{\circ}$ de octubre en España y no existe sanción si lo incumple). Si vemos el problema desde el punto de vista del Ordenamiento en su conjunto existen actuaciones jurídicas que en esos supuestos pueden suplir a la sanción en sentido estricto. (Así el control político en el Parlamento: voto de censura contra el gobierno que incumple el deber de presentar 
los presupuestos en el tiempo previsto, o pérdida de votos del partido del gobierno en las elecciones por el rechazo del electorado ante el incumplimiento de ese deber de presentar los presupuestos en el plazo debido).

4) En la Teoría del Derecho a partir de Hohfeld, deber jurídico es correlativo de derecho subjetivo y opuesto a libertad.

Los deberes correlativos al derecho subjetivo pueden ser positivos si consisten en un hacer, o negativos si consisten en no hacer u omitir. Se tiene un deber cuando alguien tiene el derecho de exigir un comportamiento o la omisión de un comportamiento. Se tiene asimismo un deber cuando no se tiene libertad, es decir, cuando no se puede impedir que otro exija un comportamiento o la omisión de ese comportamiento. Si alguien no tiene la libertad de hacer algo es porque tiene el deber de no hacerlo. Hay que afirmar que existen deberes jurídicos que no tienen como correlativo un derecho subjetivo (los deberes respecto a los animales, y muchos deberes fundamentales, el deber de la educación, por ejemplo).

c) Los deberes jurídicos se pueden clasificar con arreglo a muy diversos criterios:

1) Pueden ser específicos si su correlativo es el derecho subjetivo de una persona concreta (el titular de un crédito que se debe pagar por el deudor) y genéricos si no tienen como correlativo un derecho subjetivo de una persona concreta, sino el derecho subjetivo de cualquier persona que se encuentre en una determinada situación (el deber de asistencia a una persona herida o accidentada).

2) Pueden ser positivos si consisten en hacer, y negativos si consisten en no hacer o en soportar determinadas conductas.

3) Por su forma de producción normativa pueden ser creación del Derecho legal (lo más habitual) o del Derecho judicial (en el supuesto que Dworkin recoge del deber de no beneficiarse del propio hecho delictivo en el caso Riggs V. Palmer).

4) Por el sujeto titular pueden ser del individuo, de las comunidades sufraestatales (familia, partidos, sindicatos) y de los Estados (en la esfera interna o en la esfera internacional).

d) Con todas estas precisiones podemos estipular el uso del concepto deberes fundamentales como aquellos deberes jurídicos que se refieren a dimensiones básicas de la vida del hombre en sociedad, a bienes de primordial importancia, a la satisfacción de necesidades básicas o que afectan a sectores especialmente importantes para la organización y el funcionamiento de las Instituciones públicas, o al ejercicio de derechos fundamentales, generalmente en el ámbito constitucional.

El ejercicio de un deber fundamental no reporta beneficios exclusivamente al titular del derecho subjetivo correlativo, cuando existe, sino que alcanza una dimensión de utilidad general, beneficiando al conjunto de los ciudadanos y a su representación jurídica, el Estado.

A diferencia de los derechos fundamentales, cuya raíz ética previa (la moralidad de los derechos fundamentales) es evidente, los deberes fundamentales son, en ocasiones, consecuencia de la convención y del ejercicio del poder soberano, titular de la producción normativa. Será difícil 
encontrar una raíz moral al deber de contribuir con la prestación personal en el ejército por medio de las armas, al servicio al país. Incluso para las modernas corrientes defensoras de la objeción de conciencia se pueden encontrar argumentos morales contra ese deber.

\section{C) El Contenido de los Deberes Fundamentales.}

a) En el propio origen del sistema político moderno podemos encontrar la raíz de algunos de los deberes fundamentales actuales. La justificación contractualista clásica construida sobre una ficción racional (Pufendorf, Hobbes, Locke, Rousseau, Kant), pese a las diferencias entre esos autores, permite la elaboración de una teoría de los deberes fundamentales que ha sobrevivido hasta nuestros días. A ella se debe añadir el renacimiento del contractualismo en la actualidad desde posiciones también muy plurales (Rawls, Nozick, Buchanan, Habermas) que no permiten hablar de un solo neocontractualismo (Vallespin).

Una construcción racional desde estas corrientes contractualistas permite justificar la existencia de un modelo de deberes recíprocos en el propio origen de la sociedad política y del Estado, en una situación comunicativa ideal. Los deberes serán de los ciudadanos y de los gobernantes y se explican entrelazando el origen del poder y su función y el papel que los ciudadanos desempeñan.

El poder, el Estado es aceptado y consentido por la persona para la seguridad de todos, la salvaguardia y desarrollo de la comunidad y la protección de los derechos de la persona. Con esa finalidad los hombres se unen en sociedad y se sitúan bajo la protección del Estado.

El deber del poder político, de las instituciones, de los operadores jurídicos, será procurar esa salvaguardia de la seguridad de la libertad y de la igualdad y el deber de los ciudadanos de una sociedad así constituida, y donde ellos pueden participar en la elaboración de esos fines, será el de obedecer al Derecho consecuencia de la acción del poder político.

Desde su punto de vista Rawls (Teoría de la Justicia) justifica también el deber de gobierno y el deber de obediencia por medio del primero de los deberes naturales que él establece, el deber positivo de justicia porque «si la estructura básica de la sociedad es justa, o todo lo justo que es posible esperar dadas las circunstancias todos tienen un deber natural de hacer lo que se les exige». A través del deber de gobierno se persigue una sociedad justa y ello genera el deber de obediencia de las normas de esa sociedad justa. El deber de gobierno, tal como aquí lo hemos caracterizado, trae como consecuencia la legitimidad del sistema y supone que «la pretensión que acompaña a un orden político de ser reconocido como correcto y justo no está desprovista de buenos argumentos. Legitimidad significa el hecho de merecimiento de reconocimiento del ejercicio del deber de gobierno como correcto y justo.

Para Hart la justificación del deber de obediencia deriva del contenido mínimo de Derecho natural: «algunas generalizaciones muy obvias referentes a la naturaleza humana $\mathrm{y}$ al mundo en que los hombres viven...; en la medida en que sigan siendo verdaderas, hay ciertas reglas 
de conducta que toda organización social tiene que contener para ser viable...». Estas que se refieren a la restricción del uso de la violencia que se traduce en matar o en causar daños corporales, a una igualdad aproximada que exige un sistema de abstenciones o concesiones mutuas (base de la obligación moral y jurídica) un altruismo limitable que exige también un sistema de abstenciones mutuas, unos recursos limitados que hacen indispensable alguna forma mínima de propiedad (aunque no necesariamente de propiedad individual), y una garantía por medio de sanciones centralmente organizadas, de que aquellos que obedecen voluntariamente no serán sacrificados a quienes no lo hacen.

Sólo con este contenido se puede justificar el deber de obediencia porque sin él no sería posible llevar a cabo el propósito mínimo de supervivencia que los hombre tienen al asociarse entre sí.

Se puede también justificar el deber de gobierno con el punto de vista de Hart como el que corresponde al poder, y es esperado por los hombres al asociarse, de realizar estos objetivos que hacen viable la sociedad.

Los deberes de gobierno y de obediencia al Derecho pueden ser calificados de fundamentales, puesto que están en el origen, en la justificación y en el funcionamiento viable y posible de una sociedad política. Tienen una indudable dimensión racional, aunque también la historia ha modulado su sentido y su perfil en cada tiempo histórico.

En los orígenes del Estado liberal el deber de gobierno se concretaba a través del Derecho en la realización de las funciones de garantía de la acción de los particulares y de represión de las violaciones de ese orden garantizador. En el Estado social, se añade a esas funciones la función promocional (Bobbio) como acción positiva de los poderes públicos para satisfacer las necesidades básicas de los hombres. Eso supone que el deber de gobierno más unitario y concentrado y fundamentalmente planteado como deber negativo, se descompondrá en una serie de deberes positivos vinculados a la satisfacción de derechos de crédito (principalmente económicos, sociales y culturales) derivados del valor igualdad.

En los orígenes del Estado Liberal el deber de obediencia tenía como contrapartida, si no existía reciprocidad del deber de gobierno, el derecho de resistencia. Poco a poco por la influencia kantiana de la obediencia incondicionada, por la institucionalización dentro del sistema de la resistencia (garantías procesales, libertad de expresión, de prensa, de manifestación, etc.) y por el auge del positivismo, el derecho de resistencia perdió sentido y justificación. Hoy, después de la 2. ${ }^{\text {a }}$ Guerra Mundial, de nuevo el tema de la obediencia al Derecho ha adquirido importancia (Radbruch, Raz, Passerin d'Entreves, González Vicén, Elías Díaz) y se han planteado teorías que justifican la desobediencia civil, o la objeción de conciencia frente al Derecho injusto. Sin embargo las razones que justifican el deber de obediencia en una sociedad democrática capaz de integrar desobediencia civil y objeción de conciencia permiten, en este momento histórico, seguir sosteniendo su viabilidad (Nino).

Estos deberes fundamentales de gobierno y de obediencia al Derecho, se convierten en jurídicos si se incorporan al Ordenamiento como ya se ha explicado. Pese a su carácter radical, básico o cimentador de 
la propia sociedad política, se pueden incorporar al Derecho positivo en un sistema con un hecho fundante básico, con un poder que participe de los valores democráticos que hemos señalado para justificar estos deberes.

El deber de gobernar, en el sentido que aquí se indica, se encuentra en textos como la Declaración de derechos del buen pueblo de Virginia (1776), en la Declaración de Independencia de los Estados Unidos (1776) y en las Declaraciones francesas (1789, 1793).

El deber de obediencia al Derecho se formula en el contractualismo clásico, condicionado al cumplimiento por el poder, del deber de gobernar y aparece en los textos consagrado en su dimensión opuesta como derecho de resistencia a la opresión (Declaración de Virginia, Declaración francesa de 1793).

También, Constituciones actuales como la Italiana o a la Española, recogen el deber de obediencia al Derecho (en este último caso incluyendo también el deber de los gobernantes, lo que sin duda constituye una buena razón más de equiparación entre gobernantes y gobernados para justificar la obediencia de los ciudadanos).

El deber de gobierno se descompone en los innumerables deberes que corresponden a los poderes públicos y que en algunos casos se corresponden, como hemos visto con derechos subjetivos de los ciudadanos.

b) Junto a estos deberes fundamentales podemos señalar aquellos que se basan en razones de organización del Estado para subvenir en la satisfacción de necesidades o para la realización de funciones públicas, y que por su importancia son recogidos en la Constitución, o en leyes que encuentran su fundamento en una norma de producción recogida en la Constitución (la norma que manda al legislador establecer una Ley de Jurado, en la que se recoge el deber de participar como jurado, si se es escogida y se reúnen los requisitos establecidos en la misma Ley.

Estos deberes pueden ser de dos tipos. Pueden suponer el desempeño de funciones públicas. Son los deberes de función (Biscaretti di Ruffia). En segundo lugar pueden ser deberes prestacionales que suponen obligaciones de hacer para todos los ciudadanos o para determinada clase de ciudadanos (funcionarios u otras clases de operadores jurídicos).

Los deberes de función pueden asumir la función de jurado o el deber de voto (Bélgica, varios cantores suizos, Hungría y Dinamarca, por ejemplo). En Italia existió deber de votar en las elecciones a la Asamblea constituyente de 1946. El artículo 48 de la Constitución señala que el ejercicio del voto es un deber cívico, expresión ambigua, aunque se puede deducir que es un deber jurídico porque se recoge en la Constitución y porque se fían sanciones en caso de incumplimiento del deber.

Los deberes de prestación general (válidos para todos los ciudadanos, son principalmente dos: el deber de prestación del servicio militar y el deber de contribuir por medio del sistema tributario al sostenimiento de los gastos públicos. Los deberes de prestación especial son los de clases de ciudadanos como los funcionarios, los jueces y otros operadores jurídicos (como el deber de imparcialidad, el deber de resolver todas las prestaciones que se presenten ante ellos, o el deber de cumplir las funciones 
públicas con disciplina y honor, y de prestar juramento en su caso, art. 54 de la Constitución Italiana).

Los deberes fundamentales más comunes recogidos en Constituciones posteriores a la segunda guerra mundial, son los que hemos denominado deberes de prestación general.

El deber de contribuir a la defensa de la Nación se encuentra en el artículo 52 de la Constitución Italiana, en el artículo 30 de la Constitución Española y en el artículo 12a de la Ley Fundamental de Bonn. Estamos ante un deber fundamental que no tiene un derecho subjetivo fundamental correlativo. Se trata de una prestación personal de realización del servicio militar que tiene como finalidad la integración temporal de ese individuo en las fuerzas armadas. Durante su realización, el ciudadano se encuentra en una situación de sujeción especial que limite algún derecho fundamental (expresión, reunión, petición, garantías procesales, en cuanto algunas sanciones de plano derivadas de la disciplina militar suponen limitación del derecho a la audiencia previa, a la defensa o a la presunción de inocencia, y derecho al juez preestablecido por la Ley, al quedar sometido en algunas materias a la jurisdicción militar).

Este deber está limitado por el derecho a la objeción de conciencia que supone la posibilidad de negarse a prestar el servicio militar por motivos de conciencia o por creencias de orden religioso, moral, filosófico, etc. (Este derecho se reconoció por primera vez durante la Revolución francesa por medio de un Decreto que eximió de la prestación a los anabaptistas). Se reconoce recientemente en nuestra cultura jurídica (Francia 1963, Italia 1972, Alemania 1949, España 1978).

El Consejo de Europa por medio de una resolución de la Asamblea Parlamentaria de 1967, reconoce que la objeción de conciencia es un derecho subjetivo, derivado del derecho a la libertad de pensamiento, conciencia y religión (art. 9 del Convenio Europeo de derechos humanos).

El deber de contribuir por medio del sistema tributario al sostenimiento de los gastos públicos se recoge en la Constitución Italiana en el artículo 53, y en la Constitución Española en el artículo 31. No aparece ese deber en la Ley Fundamental de Bonn, ni tampoco en el texto de la Constitución Francesa de 1958, aunque sí en el artículo 13 de la Declaración de 1789, vigente por medio del Preámbulo de la Constitución de la IV República, a su vez en vigor de acuerdo con el Preámbulo de la Constitución de la V República.

Este deber se cumple según la capacidad económica, que es una concreción del valor igualdad como diferenciación (la consideración como relevante de la riqueza para fijar la contribución de cada uno). El deber se cumple normalmente con la garantía de la reserva de Ley para la fijación de los tributos.

c) Finalmente debemos referirnos a los deberes fundamentales de los ciudadanos o de los poderes públicos que son correlativos con la existencia de derechos subjetivos.

En esta situación se encuentran los deberes negativos de ciudadanos o de poderes públicos obligados a respetar derechos fundamentales de los que son titulares otros ciudadanos o grupos en que estos se integran (derecho a la vida, derecho de reunión, libertad de prensa, derecho de 
huelga, etc.). A veces técnicamente si llevamos a sus últimas consecuencias la distinción que arranca de Hohfell, estos deberes son más bien no derechos si su correlativo es una libertad. Esto es una prueba de los matices por los que hay que aceptar una clasificación que puede llevar a conclusiones rígidas.

Asimismo se pueden señalar los deberes positivos de los poderes públicos ya citados que suponen el incumplimiento de prestaciones exigibles por los titulares de derechos de crédito frente a esos poderes públicos (derecho a la sanidad, a la seguridad social, a la educación, etc.).

Se puede hablar en algunos casos de deberes positivos de los particulares (por ejemplo en relación con la libertad sindical, los deberes de los empleadores de facilitar locales para reuniones, o de liberar de trabajo a los representantes sindicales). 